Food hygiene knowledge in adolescents and young adults

\author{
Barbara A Mullan \\ School of Psychology and Speech Pathology \\ Curtin University \\ Western Australia, Australia
}

\author{
Cara Wong \\ School of Psychology \\ The University of Sydney \\ Sydney, Australia \\ Jemma Todd \\ School of Psychology \\ The University of Sydney \\ Sydney, Australia \\ Esther L Davis \\ School of Psychology \\ The University of Sydney \\ Sydney, Australia \\ Emily Kothe \\ School of Psychology \\ Deakin University \\ Melbourne, Australia
}

Corresponding author: Barbara A Mullan

Corresponding Author's Email: barbara.mullan@curtin.edu.au 


\begin{abstract}
Purpose: The aim of this study was to utilise the comprehensive Food Safety Knowledge Instrument to compare food hygiene knowledge across a population of high school and university students in Australia and the United Kingdom.

Design/methodology/approach: Four hundred and seventy-five students from secondary schools and universities in Australia and the United Kingdom took part in a survey, which included a Food Safety Knowledge Instrument and demographic items.
\end{abstract}

Findings: Food safety knowledge was generally very low. High school students had a mean score of only $38 \%$, while university students just reached a 'pass' with a mean of $54 \%$. Demographics accounted for $41 \%$ of variance in food knowledge scores. Female gender, being at university rather than high school, and living out of home rather than with parents were associated with greater food knowledge. Residing in Australia rather than the United Kingdom and being older were also associated with greater knowledge; however, these findings were subsumed by education group. Socio-economic status was not a significant predictor of food knowledge. Practical implications: Identifying demographic and cultural differences in food knowledge can help to identify at-risk populations to better target in theory and knowledge based interventions.

Originality/value: This study is the first to apply the knowledge instrument in an Australian population. Understanding the baseline knowledge in this population is an important first step at developing effective interventions for food safety. 


\section{Food hygiene knowledge in adolescents and young adults}

Foodborne diseases encompass a wide spectrum of illnesses ranging from minor gastrointestinal problems to life threatening illnesses such as botulism, salmonella, cholera and hepatitis A (World Health Organization, 2007). The number of reported foodborne illnesses in Australia and worldwide has increased over the past 10 years (National Health and Medical Research Council, 2003). Approximately one quarter of the population in most high income countries, for example, Australia and the USA, experience food borne illness annually (The Food Safety Information Council, 2008, Mead et al., 1999). Consequently, food poisoning is one of the most widespread public health problems in high-income countries. In Australia, it has been reported that there is an average of 120 deaths at a cost of approximately $\$ 1.25$ billion annually (NSW Food Authority, 2009). In the United Kingdom, foodborne disease affects 5.5 million consumers annually, or 1 in 10 people (Food Standards Agency, 2002). Foodborne illness causes 687 deaths (Adak et al., 2005) and costs approximately $£ 1.5$ billion per year (Redmond and Griffith, 2006). In the United States of America, these numbers may be as high as 76 million cases of food poisoning per year with 325,000 hospitalisations and 5,000 deaths annually (Mead et al., 1999). However, high as these figures are, they are believed to be consistently underestimates of true incidence rates, as not all cases of foodborne illness are reported to the relevant authorities (Crerar et al., 1996, Day, 2001, Mead et al., 1999). Reported cases of food poisoning are thought to represent only $10 \%$ of actual cases (Lacey, 1993).

There are several practices that the consumer can implement to prevent food contamination while preparing, cooking and storing food. These include thoroughly 
reheating foods, washing cutting boards and utensils when switching between foods to prevent cross-contamination, storing foods appropriately, correct hand washing, storing foods at the correct temperature, and maintaining good personal hygiene. It has been estimated that at least $60 \%$ of food poisoning originates in the home rather than with food manufacturers of restaurants (Worsfold, 1997). It is because of principles like these that the last defence against food poisoning is often regarded as resting with the consumer (Gilbert, 1983). However, despite foodborne illness being a significant and persistent health issue is also one of the most preventable.

\section{The role of knowledge}

It is a widely held belief that much of foodborne illness is the result of a lack of education and awareness of hygienic food handling practices, and that an increase in food hygiene education will lead to a comparative decrease in the instances of food poisoning (Griffith et al., 1998). Participants in a study by Green et al. (2005) identified education as an essential prerequisite for engaging in hygienic food handling behaviours and respondents' portray food safety knowledge and their perceived level of control over food safety practices as being the most significant factors in feeling confident as to the safety of food cooked at home. Knowledge as a predictor of behaviour has found support in other studies as well (Food Standards Australia New Zealand, 2008). In an comparable field, a meta-analysis of 35 studies by Shaikh et al. (2008) recognized knowledge as being one of the strongest predictors of fruit and vegetable consumption.

As has been argued in the context of other health guidelines (e.g. fruit and vegetable consumption: Kothe and Mullan, 2011), an appropriate level of knowledge may be a necessary, but not sufficient, determinant of adherence to safe food handling practices. Indeed the important role that knowledge plays in behavioural performance 
is recognised in both the Integrated Behavioural Model (Fishbein and Yzer, 2003) and the Information, Motivation and Behavioural Skills model of behaviour (Fisher and Fisher, 2002). Both models would imply that knowledge of key food safety concepts is required to allow adherence to safe food handling practices.

While a steady increase in foodborne illness over the last 10 years would suggest otherwise, consumers by and large believe that they have adequate knowledge of hygienic food handling practices (Haapala and Probart, 2004). This disparity between food handling knowledge and self-reported food handling behaviour is reflected in the literature (Bruhn and Schutz, 1999, Frewer et al., 1995, Gettings and Kiernan, 2001, Haapala and Probart, 2004, Redmond and Griffith, 2003). For example, while $97 \%$ of participants in a study conducted by Byrd-Bredbenner and colleagues (2007a) self-reported their hygienic food handling knowledge as at least fair, as many as $60 \%$ failed to wash their hands following direct contact with raw poultry. Similarly Maurer (2006) found that whilst 76\% of young adults reported washing their hands properly all or most the time, only 53\% were actually observed performing the recommended hand washing practices. Perhaps even more troubling is that some studies have found as many as 10 to $50 \%$ of individuals intentionally engage in risky food handling behaviours (Redmond and Griffith, 2003, Bruhn and Schutz, 1999) as they believe themselves to be immune from foodborne illness, due to factors such as optimism bias.

Studies conducted on adults have indicated that food safety knowledge tends to increase with age and practice (Byrd-Bredbenner et al., 2007a). Females tend to have higher scores than males in food safety knowledge, and younger consumers (under 19 years old) show the most inappropriate practices and significantly lower food hygiene knowledge. These groups may have the least food handling experience 
and it is further hypothesised that decreased knowledge may be due to changes in educational system (elimination of home economics classes), increased numbers of working mothers and a growing reliance on convenience, take away and restaurant foods (Williamson et al., 1992, Altekruse et al., 1999)

\section{Food safety and age trends}

Childhood is an important time for developing knowledge and skills about food hygiene and preparation, however, teaching of these skills in schools is declining (Mullan, 2009). A study investigating primary and secondary schools in the UK found that teaching of food hygiene was not in the national curriculum in England and Wales (Mullan, 2009). There was a slight increase in the instruction of food hygiene between primary and secondary schools, however in secondary schools this was only in students who studied food related areas. Haapala and Probart (2004) investigated food safety knowledge in a group of students from the USA (years 7 and 8) and found that they only had a fair level of knowledge (mean of 7 out of 10 questions correct), with no difference between genders. Particularly, students performed badly on questions relating to cooking and cleaning (e.g. safe temperatures to cook chicken, cleaning cutting boards between raw meat and other food items). However, the majority of students (92\%) did prepare snacks and meals at home and $21 \%$ reported they had been sick due to something they ate. One fifth of the students also reported frequently taking risks in personal food handling, suggesting low perceived susceptibility. A recent study in the USA found that most children in early high school (mean age 12.6) did prepare food at least weekly and while they knew that food could make them ill they were unsure or unaware of the exact mechanisms (Byrd-Bredbenner et al., 2010).

\section{Aims}


The aim of this study was to utilise the comprehensive food-safety knowledge instrument developed by Byrd-Bredbenner et al. (2007a) to compare the food hygiene knowledge across a population of high school and university aged students. As mentioned, younger age groups are most at risk for inappropriate food handling behaviours and consequently foodborne disease. Byrd-Bredbenner et al. (2007b) found that young adults aged 17 to 19 had the lowest food safety knowledge; however, very few studies have investigated the food hygiene knowledge of children or adolescents. The questionnaire contains 5 scales which cover key food safety concepts. These include cross contamination and disinfection procedures; safe times/temperatures for cooking/storing foods; groups at greatest risk for foodborne disease; foods that increase the risk of foodborne disease; and foodborne pathogens. This questionnaire has been shown to have good reliability $(\mathrm{r}=.92)$ and validity, and is appropriate to use with a wide range of ages from adolescent to adults. This study is the first to apply the knowledge instrument in an Australian population. Understanding the baseline knowledge in this population is an important first step at developing effective interventions for food safety.

\section{Method}

\section{Recruitment}

University aged participants were recruited from an undergraduate psychology population at an Australian University. The study was approved by the University's Human Research Ethics Committee. Participants received course credit for participating in the study.

Secondary school participants were recruited from Australia and the United Kingdom across 2007 and 2008. Participants were recruited from both a range of schools in urban and rural areas and of different types (e.g. public and private, single 
sex and co-education, religious and secular). The study was approved by Human Research Ethics, and a separate ethics protocol was approved by the Catholic Education Office to recruit from Catholic schools. Schools were contacted from school directories, for example the National Education Directory in Australia and the Department of Education and Science in the UK. The researchers made email or phone contact with the schools to determine if they were interested in participating in the study. If the school was interested, they were told to choose appropriate classes or years where the students were between 11 and 18 years of age. Although twenty-five schools agreed to participate initially, many did not continue on to be involved in the research, primarily due to time constraints, workload demands, or failure to correspond with the researchers. The final sample was recruited from three Australian schools in New South Wales (NSW), and four schools from the UK in areas such as Worcester, Gloucester, Yorkshire and Hampshire. Parent consent was obtained prior to student participation.

In total, 475 participants took part in the study; 205 were from secondary schools in Australia or the UK (113 females, 92 males), and 268 were university students (194 females, 74 males).

\section{Materials}

Food safety knowledge was measured using an online version of the Food Safety Knowledge questionnaire (Byrd-Bredbenner et al., 2007b). This is a validated and standardised questionnaire that covers many facets of safe food handling. The questionnaire is scored out of 89 , with scores converted to a percentage and the pass rate set at 50\%. The 89 items assess knowledge across the 5 subscales listed in Table 1. Participants received a score of one for each correct response. Each item was either 
a multiple choice question or true/false response. The total score was calculated as a percentage.

Demographic questions were also included. Participants were asked to state their age, and select their gender (male/female), the primary occupation of their father as a proxy for socio-economic status (higher managerial or professional/intermediate managerial or professional/supervisor or junior/skilled manual workers/semiskilled and unskilled manual workers/unemployed/student), and their living situation (with parents/rental property with friends/rental property with partner/catered or un-catered college/own home). Whether the participant was recruited from a high school or university, and their country of origin (Australia/UK) were also recorded.

\section{TABLE 1 NEAR HERE}

\section{Procedure}

The food safety questionnaire was administered online along with demographic items. Participants were provided with an individual identification number and a link to the online questionnaire. For school students, teachers assisted with the administration of the procedure and students completed the questionnaire.

\section{Results}

\section{Demographics}

Four hundred and seventy-one participants completed the study; 222 high school students and 249 university students, with 366 born in Australia and 97 born in the United Kingdom. Mean age of participants was 17.3 ( $S D=4.8$; range $11-52)$ years, and the majority were female $(66.6 \%)$ and lived with their parents $(80.9 \%)$. Regarding socio-economic status, the majority (56.8\%) of fathers of participants were employed in an intermediate or higher managerial position, 19.4\% were skilled 
labourers, $8.6 \%$ were students, $5.6 \%$ were supervisors or clerics, $4.5 \%$ were unemployed, and 4\% were semi-skilled or unskilled manual workers.

Food safety knowledge scores

The results of the food safety questionnaire showed that in general, knowledge was very low (see Table 2). Participants from the high school population had a mean score of only $38 \%(S D=11.3$; range $21-45 \%)$, while participants from the university population just reached a 'pass rate' with a mean score of $54 \%(S D=9.9$; range $26-$ 70\%). Participants were most knowledgeable about foods that increased risk of foodborne disease and least knowledgeable about common food sources of foodborne disease pathogens.

\section{TABLE 2 NEAR HERE}

\section{Predictors of knowledge scores}

Univariate Analysis of Variance was used to explore socioeconomic status (i.e. father's occupation) and living situation differences in knowledge. Significant differences in knowledge scores were found for individuals in different living situations, $\left(f_{5,454}=5.84, p<.001\right)$. Post-hoc tests using the Tukey HSD procedure revealed that those who lived with their parents had significantly lower knowledge scores $(\mathrm{m}=40.80, \mathrm{SD}=6.14)$ than those who were renting $(\mathrm{m}=47.54, S D=8.71 ; p=.001)$ and those who were living in their own home $(\mathrm{m}=52.40, S D=7.03)$. There were not significant differences in knowledge scores, depending on socioeconomic status $\left(f_{7,388}=1.92, p=.065\right)$.

Relationships between knowledge scores and the demographic variables of age, gender, country of birth and education group were investigated using a hierarchical multiple regression analysis (see Table 3). Age, gender, and country of birth were entered in the first step, followed by education group in the second step, as 
it was assumed that age and education group would be confounded and may not explain additional variance above each other. However, being more highly educated may also explain additional variance over age trends, and therefore this variable was included in the second step.

In the first step the overall model was statistically significant, explaining $31.7 \%$ of the variance in knowledge $\left(f_{3,464}=71.68, p<.001\right)$. All three variables were significant independent predictors, with age accounting for $10.8 \%$ of the variance, gender accounting for $11.4 \%$ of the variance, and country of birth accounting for $4.5 \%$ of the variance in scores, each controlling for the other variables. When education group was added in the second step, the overall model remained significant, explaining $44.1 \%$ of variance in knowledge scores $\left(f_{4,463}=91.25, p<.001\right)$. Gender and education group remained significant independent predictors, explaining $9.0 \%$ and $18.1 \%$ of the variance in knowledge scores respectively, whereas country of birth and age were not. Holding all other predictors constant, being of female gender and at university rather than high school were associated with greater levels of knowledge.

\section{TABLE 3 NEAR HERE}

\section{Discussion}

Food borne illnesses have cause approximately 120 deaths in Australia and 687 deaths in the United Kingdom annually (NSW Food Authority, 2009; Food Standards Agency, 2002), with estimates of foodborne disease as high as 1 in 10 people (Food Standards Agency). Food hygiene in the home has been identified as an important way to prevent food borne illnesses (Worsfold, 1997., Gilbert, 1983).

Despite findings, knowledge about food hygiene and the prevention of food borne illnesses tends to be surprisingly low (Byrd-Bredbenner et al., 2007). The aim of this study was to explore food hygiene knowledge across high school and university-aged 
students, and across two countries; Australia and the United Kingdom. Better understanding of food hygiene knowledge and the role of demographic factors is an important step in both developing effective interventions that may incorporate knowledge, as well as enabling more effective tailoring of such interventions to groups that are more at risk of food borne illness.

Overall, low levels of knowledge were found in participants, with school students correctly answering $38 \%$ of knowledge measure items, and university students correctly answering $54 \%$ of the knowledge measure items. These levels of knowledge are even lower than those reported in Byrd-Bredbenner et al.'s (2007a) study. Low knowledge levels may therefore be a barrier to implementing safe food hygiene practices, particularly amongst school students who may not be aware of some of the sources of food-borne illnesses that can be avoided in the home.

As expected, demographic variables were significant predictors of food hygiene knowledge, and explained a substantial $44 \%$ of the variance in knowledge. In particular, those who were female, and university (rather than school) students, living at home, and residing in Australia had greater levels of food hygiene knowledge; however age and country of birth effects were no longer significant when education group was included. These results will be explored in turn.

In the first step of the regression model, age was a significant predictor of food knowledge, and independently explained $11 \%$ of the variance. This is as expected, and in accordance with previous research suggesting that knowledge increases with age. For example, Sanlier (2009) compared the food safety practices of young adults (14-19yrs) and adults (20+) in Turkey, and found that young adults had poorer food safety knowledge and food safety preparation. The authors argued for the necessity to find ways to improve education and knowledge on food safety. It may therefore be 
useful to design food safety interventions that include knowledge components for younger individuals.

Age effects were, however, no longer significant when education group (i.e. university or school student) was included in the model, and education group explained over $18 \%$ of the variance in knowledge, representing a large effect size. That age was no longer significant with the addition of education group was not surprising, given that individuals at university are older than school students, and also that differences between these groups may be larger than small age variations within these populations. As such, it appears that age effects have been explained and accounted for by education group. It is also possible that those who are accepted into university are more intelligent, have higher socio-economic status, or may have better access to learning materials, thus offering a greater opportunity for those students to learn about food hygiene. This notion is supported by research suggesting that better educated individuals tended to have a better diet (e.g. less meat, more vegetables, and less unhealthy snacks) than those who had lower education levels; an effect that was not explained by age (Fraser et al., 2000). Further research could explore the role of learning opportunities as a predictor of knowledge, as this could form the basis of tailored interventions to increase food hygiene practices.

In the current study, females tended to have greater food knowledge than males. Such differences are consistent with previous findings in the United States (e.g. Byrd-Bredbenner et al., 2007a) and in Europe (Sanlier and Konaklioglu, 2012), and are also found for food hygiene behaviours such as hand-washing (Anderson et al., 2008). Males may therefore be at greater risk of foodborne illness than females, and future interventions should be designed accordingly to target male populations. 
Those who lived at home with their parents had lower levels of food knowledge than those who lived in rental properties or in their own home. It is likely that age is a confounder, such that those who were renting and living in their own home were older than those who lived at home. However, it is also possible that those who live at home have less responsibility for food preparation, and therefore had not encountered as many opportunities to learn about food hygiene and practice safe food handling (Byrd-Bredbenner et al., 2007a).

Australians had higher levels of food knowledge than those residing in the United Kingdom. However, country differences in food knowledge were no longer relevant when education group was added to the regression. As university students could only be recruited from Australia, the most likely explanation for this finding is that country and education group were confounded, and the differences between school students and university students were larger than the differences between the school students recruited from Australia and the United Kingdom. However, the initial country differences observed could also be partly explained by a range of social, economic, and cultural differences (Wilcock, Pun, Khanona, \& Aung, 2004). Although there is limited cross-country or cross-culture examination of food safety and food knowledge, Jussaume and Judson (1992) found that those living in Japan were significantly more concerned about food safety than those living in the United States. However, in their study as in the current study, this effect was mediated by circumstantial differences, such as number of children, age, income and education; those of similar circumstances had similar food safety concerns, regardless of country. Further exploration of potential cultural and country differences in food knowledge is warranted. 
That food hygiene knowledge scores varied across demographic factors such as gender and education group is promising, as it provides an avenue for more specified food-hygiene knowledge interventions that target those who need them most. In particular, school-age males may be more at risk of foodborne illnesses due to lower knowledge levels, and future interventions could target this population.

There has been research suggesting that knowledge may be necessary, but not sufficient, for behaviour change in food-related behaviours (Kothe and Mullan, 2011). Even when levels of knowledge are high there is frequently a disconnect between knowledge and behaviour (Ansari-Lari et al., 2010), and a recent intervention that included knowledge was unsuccessful in in improving food hygiene in a sample of Australian university students, even though increases in knowledge were found (Mullan \& Wong, 2010). It is possible that other factors are also important in motivating food hygiene, such as desire to change behaviour, impulsivity and selfcontrol, attitudes, and social images; these factors should be investigated to determine whether they explain differences in food hygiene behaviour, and if so whether appropriate interventions can be designed to target these factors in addition to increasing knowledge.

A recent systematic review of food hygiene interventions suggested that food hygiene is modifiable, however, the quality of the studies was generally poor, and many relied on self-report changes (Milton and Mullan, 2010), despite previous research suggesting that self-reported food hygiene do not match actual practices (Maurer, 2006).

To further develop this field of research, theory-based interventions may offer more effective interventions. For example, the theory of planned bheaviour has been effectively used to explain and change a range of food-related behaviours (Webb and 
Sheeran, 2006). In the area of food hygiene, Milton and Mullan (2012) recently conducted a Theory of Planned Behaviour based intervention designed to also improve knowledge, as well as attitudes, subjective norms, and perceived behavioural control. This intervention was effective in improving food hygiene behaviour in young adults, and therefore applying models such as the Theory of Planned Behaviour to food hygiene may create more effective interventions. In working towards such food hygiene interventions, food knowledge could form a basis that is then built upon by theoretically driven interventions.

Limitations of the current study must be considered. Actual food hygiene behaviours were not measured, and therefore it cannot be assumed, even with low knowledge scores, that the current sample had poor food hygiene. However, previous research has suggested that knowledge may be necessary (albeit not sufficient) for behaviour (Kothe and Mullan, 2011); and the relationship between food knowledge and behaviour warrants further investigation. Secondly, identifying demographic differences in food knowledge does not offer ways to change knowledge; however identifying both baseline levels of food knowledge, and populations at risk for specified targeting of such interventions, are equally important for this field of research, and suggest that poor knowledge may be a limitation to behavioural implementation, particularly in young males.

Using the results of the current study, tailoring such interventions may help to improve their effectiveness. Empirically rigorous interventions using knowledge and theory-based intervention components, and that are designed for specific at-risk groups (such as young males who live at home) would be very beneficial to this field of research. 


\section{References}

ADAK, G., MEAKINS, S., YIP, H., LOPMAN, B. \& O'BRIEN, S. 2005. Disease risks from foods: England and Wales, 1996-2000. Emerging Infectious Diseases, 11, 365-72.

ALTEKRUSE, S., YANG, S., TIMBO, B. \& ANGULO, F. 1999. A multi-state survey of consumer food-handling and food-consumption practices. American Journal of Preventive Medicine, 16, 216-221.

ANDERSON, J. L., WARREN, C. A., PEREZ, E., LOUIS, R. I., PHILLIPS, S., WHEELER, J., COLE, M. \& MISRA, R. 2008. Gender and ethnic differences in hand hygiene practices among college students. American Journal of Infection Control, 36, 361-368.

ANSARI-LARI, M., SOODBAKHSH, S. \& LAKZADEH, L. 2010. Knowledge, attitudes and practices of workers on food hygienic practices in meat processing plants in Fars, Iran. Food Control, 21, 260-263.

BRUHN, C. \& SCHUTZ, H. 1999. Consumer food safety knowledge and practices. Journal of Food Safety, 19, 73-87.

BYRD-BREDBENNER, C., ABBOT, J. M. \& QUICK, V. 2010. Food safety knowledge and beliefs of middle school children: Implications for food safety educators. Journal of Food Science Education, 9, 19-30.

BYRD-BREDBENNER, C., MAURER, J., WHEATLEY, V., SCHAFFNER, D., BRUHN, C. \& BLALOCK, L. 2007a. Food safety self-reported behaviors and cognitions of young adults: Results of a national study. Journal of Food Protection, 70, 1917-1926.

BYRD-BREDBENNER, C., WHEATLEY, V., SCHAFFNER, D., BRUHN, C., BLALOCK, L. \& MAURER, J. 2007b. Development and implementation of a food safety knowledge instrument. Journal of Food Science, 6, 4655.

CRERAR, S. K., DALTON, C. B., LONGBOTTOM, H. M. \& KRAA, E. 1996. Foodborne disease: Current trends and future surveillance needs in Australia. Medical Journal of Australia, 165, 672-675.

DAY, C. 2001. Gastrointestinal disease in the domestic setting: What can we deduce from surveillance data? Journal of Infection, 43, 30-35. 
FISHBEIN, M. \& YZER, M. C. 2003. Using theory to design effective health behavior interventions. Communication Theory, 13, 164-183.

FISHER, J. D. \& FISHER, W. A. 2002. The information-motivation-behavioral skills model. In: DICLEMENTE, R. J., CROSBY, R. A. \& KEGLER, M. C. (eds.) Emerging theories in health promotion practice and research: Strategies for improving public health. San Francisco: Jossey-Bass.

FOOD STANDARDS AGENCY. 2002. Food Standards Agency - Survey shows concerns about food poisoning and hygiene standards [Online]. England, Wales, Northern Ireland, Scotland: Food Standards Agency. Available:

http://www.food.gov.uk/news/newsarchive/2002/feb/hygienesurvey [Accessed 17 May 2009 2009].

FOOD STANDARDS AUSTRALIA NEW ZEALAND. 2008. Consumer Attitiudes Survey 2007 [Online]. [Accessed 10th August, 2009 from http://www.foodstandards.gov.au.

FRASER, G. E., WELCH, A., LUBEN, R., BINGHAM, S. A. \& DAY, N. E. 2000. The effect of age, sex, and education on food consumption of a middle-aged English cohort-EPIC in East Anglia. Preventive Medicine, 30, 26-34.

FREWER, L. J., HOWARD, C. \& SHEPHERD, R. 1995. Consumer perceptions of food risks. Food Science and Technology Today, 9, 212-16.

GETTINGS, M. A. \& KIERNAN, N. E. 2001. Practices and perceptions of food safety among seniors who prepare meals at home. Journal of Nutrition Education, 33, 148-154.

GILBERT, R. J. 1983. Food-borne infections and intoxications--recent trends and prospects for the future. Society for Applied Bacteriology symposium series, 11, 47-66.

GRIFFITH, C., WORSFOLD, D. \& MITCHELL, R. 1998. Food preparation, risk communication and the consumer. Food Control, 9, 225-232.

HAAPALA, I. \& PROBART, C. 2004. Food safety knowledge, perceptions, and behaviors among middle school students. Journal of Nutrition Education and Behavior, 36, 71-76. 
JUSSAUME JR, R. A. \& JUDSON, D. H. 1992. Public perceptions about food safety in the United States and Japan. Rural Sociology, 57, 235-249.

KOTHE, E. J. \& MULLAN, B. A. 2011. Perceptions of fruit and vegetable dietary guidelines among Australian young adults. Nutrition \& Dietetics, 68, 262-266.

LACEY, R. W. 1993. Food-borne bacterial infections. Parasitology, 107, S75S93.

MAURER, J. Young adults report better hand washing practices than they actually practice. Ensuring Food Safety, Emergency Preparedness and Disease Prevention: The 134th Annual Meeting \& Exposition of APHA, 2006 Boston, MA.

MEAD, P., SLUTSKER, L., DIETZ, V., MCGCAIG, L., BRESEE, J., SHAPIRO, C. \& AL., E. 1999. Food-related illness and death in the United States. Emerging Infectious Diseases, 5, 607-25.

MILTON, A. \& MULLAN, B. 2010. Consumer food safety education for the domestic environment: a systematic review. British Food Journal, 112, 1003-1022.

MILTON, A. C. \& MULLAN, B. A. 2012. An application of the theory of planned behavior - a randomized controlled food safety pilot intervention for young adults. Health Psychology, 31, 250.

MULLAN, B. 2009. Using the Theory of Reasoned Action to Predict Safe Food Handling : Knowledge attitudes and social norms of children and young adults regarding food hygiene behaviour, Saarbruken, VDM Verlag Dr Muller Aktienesellschaft \& Co.

NATIONAL HEALTH AND MEDICAL RESEARCH COUNCIL 2003. NHMRC Dietary Guidelines for Australian Adults. A Guide to Healthy Eating. . Canberra: Commonwealth of Australia.

NSW FOOD AUTHORITY. 2009. Food poisoning. Available: www.foodauthority.nsw.gov.au/consumer/c-food.asp [Accessed 13th May 2009].

REDMOND, E. \& GRIFFITH, C. 2003. Consumer food handling in the home: A review of food safety studies. Journal of Food Protection, 66, 130161. 
REDMOND, E. \& GRIFFITH, C. 2006. Assessment of consumer food safety education provided by local authorities in the UK. British Food Journal, 108, 732-752.

SANLIER, N. 2009. The knowledge and practice of food safety by young and adult consumers. Food Control, 20, 538-542.

SANLIER, N. \& KONAKLIOGLU, E. 2012. Food safety knowledge, attitude and food handling practices of students. British Food Journal, 114, 469-480.

SHAIKH, A. R., YAROCH, A. L., NEBELING, L., YEH, M.-C. \& RESNICOW, K. 2008. Psychosocial predictors of fruit and vegetable consumption in adults: A review of the literature. American Journal of Preventive Medicine, 34, 535-543.

THE FOOD SAFETY INFORMATION COUNCIL. 2008. Food safety tips for young people leaving home [Online]. Redhill ACT: Food Safety Information Council. Available: http://www.foodsafety.asn.au/ [Accessed May 8th 2008].

WEBB, T. L. \& SHEERAN, P. 2006. Does changing behavioral intentions engender behavior change? A meta-analysis of the experimental evidence. Psychological Bulletin, 132, 249-268.

WILLIAMSON, D. M., GRAVANI, R. B. \& LAWLESS, H. T. 1992. Correlating food safety knowledge with home food-preparation practices. Food Technology, 46, 94-100.

WORLD HEALTH ORGANIZATION 2007. Food safety and foodborne illness. Geneva: World Health Organization, March.

WORSFOLD, D. 1997. Food safety behaviour in the home. British Food Journal, 99, 97-104. 
Table 1

Sample items and psychometric properties of each subscale of the Food Safety

Knowledge questionnaire

* Livingston reliability coefficient from Byrd-Bredbenner et al (2007b)

\begin{tabular}{|c|c|c|c|}
\hline Scale & Sample item & $\begin{array}{l}\text { Possible } \\
\text { points }\end{array}$ & $\mathrm{r}^{*}$ \\
\hline $\begin{array}{l}\text { 1. Cross } \\
\text { contamination } \\
\text { prevention and } \\
\text { disinfection } \\
\text { procedures }\end{array}$ & $\begin{array}{l}\text { The best way to keep from getting food } \\
\text { poisoning from fresh fruits and vegetables is } \\
\text { to wash them with } \\
\text { a) regular soap } \\
\text { b) hot water } \\
\text { c) anti-bacterial soap } \\
\text { d) an anti-bacterial sponge } \\
\text { e) cool running water }\end{array}$ & $0-29$ & .78 \\
\hline $\begin{array}{l}\text { 2. Times and } \\
\text { temperatures for } \\
\text { cooking and } \\
\text { storing food }\end{array}$ & $\begin{array}{l}\text { What is the recommended freezer } \\
\text { temperature for preventing food poisoning? } \\
\text { a) } \mathbf{- 1 8} \text { degrees Celsius } \\
\text { b) }-8 \text { degrees Celsius } \\
\text { c) }-4 \text { degrees Celsius } \\
\text { d) } 0 \text { degrees Celsius }\end{array}$ & $0-14$ & .72 \\
\hline $\begin{array}{l}\text { 3. The groups at } \\
\text { greatest risk for } \\
\text { foodborne disease }\end{array}$ & $\begin{array}{l}\text { People should be especially careful about not } \\
\text { eating raw seafood if they have } \\
\text { a) diabetes } \\
\text { b) HIV infection } \\
\text { c) cancer } \\
\text { d) any of these diseases }\end{array}$ & $0-28$ & .87 \\
\hline $\begin{array}{l}\text { 4. Foods that } \\
\text { increase the risk of } \\
\text { foodborne disease }\end{array}$ & $\begin{array}{l}\text { Chilling or freezing eliminates harmful germs } \\
\text { in food } \\
\text { a) true } \\
\text { b) false }\end{array}$ & $0-10$ & .80 \\
\hline $\begin{array}{l}\text { 5. Common food } \\
\text { sources of } \\
\text { foodborne disease } \\
\text { pathogens }\end{array}$ & $\begin{array}{l}\text { Listeria bacteria are most likely with which } \\
\text { food } \\
\text { a) home canned foods } \\
\text { b) raw or undercooked beef } \\
\text { c) deli meats } \\
\text { d) raw eggs or poultry } \\
\text { e) don't know }\end{array}$ & $0-8$ & .72 \\
\hline TOTAL & & $0-89$ & .92 \\
\hline
\end{tabular}


Table 2

Knowledge scores (percent correct)

\begin{tabular}{lccc}
\hline & $\begin{array}{c}\text { High school } \\
\%(\mathrm{SD})\end{array}$ & $\begin{array}{c}\text { University } \\
\%(\mathrm{SD})\end{array}$ & $\begin{array}{c}\text { Combined } \\
\%(\mathrm{SD})\end{array}$ \\
\hline Cross contamination & $38(17.4)$ & $63(13.8)$ & $52(19.7)$ \\
Safe times/temps & $39(17.4)$ & $53(16.7)$ & $47(18.3)$ \\
Food risk & $39(14.7)$ & $49(13.2)$ & $45(14.7)$ \\
Groups at risk & $45(20.3)$ & $70(19.7)$ & $59(23.4)$ \\
Pathogens & $21(16.3)$ & $26(19.2)$ & $2418.2)$ \\
Total score & $38(11.3)$ & $54(9.9)$ & $47(13.3)$ \\
\hline
\end{tabular}


Table 3

Multiple regression analyses on knowledge scores and demographic variables

\begin{tabular}{lllllll}
\hline & $\beta$ & $t$ & $\eta^{2}$ & $R$ & $\Delta R^{2}$ & $p$ \\
\hline Step 1 & & & & & & \\
Age & .320 & 7.48 & .108 & & & $<.001$ \\
Gender & .303 & 7.73 & .114 & & & $<.001$ \\
Country of birth & -.197 & -0.47 & .045 & & & $<.001$ \\
& & & & .563 & & $<.001$ \\
Step 2 & & & & & \\
Age & .062 & 1.34 & .004 & & & .181 \\
Gender & .244 & 6.77 & .090 & & & $<.001$ \\
$\begin{array}{l}\text { Country of birth } \\
\text { Education }\end{array}$ & .052 & 1.14 & .003 & & & .256 \\
group & .559 & 10.14 & .181 & & & $<.001$ \\
& & & & & .664 & \\
& & & & & .124 & $<.001$ \\
\hline
\end{tabular}

Note. $\beta=$ standardised regression coefficient, $\eta_{p}{ }^{2}=$ partial eta squared (proportion of independent variance explained) 